\title{
¿La danza clásica contemporánea, un estilo coreográfico del siglo XXI?
}

\author{
Contemporary Classical Dance: A Choreographic \\ Style from the 21st Century?
}

Clara Inés de la Rosa

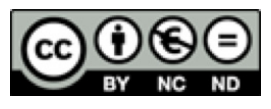

Esta obra está bajo una licencia Creative Commons Reconocimiento-No comercial-Sin Obra Derivada 


\title{
¿La danza clásica contemporánea, un estilo coreográfico del siglo XXI? ${ }^{1}$ \\ Contemporary Classical Dance:
}

\author{
A Choreographic Style from the 21st Century? \\ Clara Inés de la Rosa Barreto² \\ Universidad Autónoma del Estado de México \\ ciderb84@gmail.com
}

Recibido: 28 de setiembre del 2016 Aprobado: 22 de mayo del 2017

\section{Resumen}

El ballet durante el siglo XX se vio sujeto a transformaciones expresivas por la necesidad de mantener vigente un género con más de dos siglos de antigüedad y que parecía ajeno a las exigencias de entonces. Así, la danza se fue transfigurando, rebelándose contra su manifestación clásica. Se rompieron los esquemas rígidos de su cuerpo técnico en pro de una liberación creativa con coreógrafos, bailarines y maestros capaces de organizar un nuevo sistema técnico y estético que dio forma a la danza moderna y contemporánea. Ambos géneros dancísticos, ballet y danza contemporánea, consiguieron tolerarse y comprenderse, dando origen a la danza clásica contemporánea, desde finales del siglo XX y con toda su riqueza estética en el siglo XXI, como un nuevo estilo coreográfico que llegó a México, en este caso, con la ejecución de tres obras por parte de la Compañía Nacional de Danza (CND), lo que da cuenta de su vigencia en nuestro siglo.

Palabras clave: danza; ballet; arte; historia del arte; México; estilo; coreografía

1 Este artículo es parte de una investigación más amplia sobre el mismo tema, con la que se obtuvo el grado de Maestría en Humanidades, Estudios Históricos.

2 Magíster en Humanidades, Estudios Históricos, Universidad Autónoma del Estado de México. 


\begin{abstract}
:
The ballet during the twentieth century was subject to expressive transformations, due to the need to maintain a genre with more than two centuries old and that seemed oblivious to the demands of that time. Thus, the dance was transfigured, rebelling against its classical manifestation. They broke the rigid schemes of its technical body, for a creative liberation with choreographers, dancers and teachers capable of organizing a new technical and aesthetic system that shaped modern and contemporary dance. Both dance genres, ballet and contemporary dance, were able to be tolerated and understood, giving rise to contemporary classical dance, since the end of the twentieth century and with all its aesthetic wealth in the XXI century, as a new choreographic style that arrived in Mexico in this Case, with the execution of three works by the CND, which accounts for its validity in our century.
\end{abstract}

Keywords: dance; ballet; art; history of art; Mexico; style; choreography. 
El ballet en el mundo durante el siglo XX se vio sujeto a transformaciones expresivas, como respuesta a la inquietud de los creadores dancísticos por mantener vigente un género con más de dos siglos de antigüedad y que comenzaba a parecer ajeno a las necesidades artísticas que un vertiginoso siglo XX exigía. En gran medida, debido a la violenta sacudida que provocarían las dos Grandes Guerras en las estructuras sociales, económicas y culturales de la humanidad, se trató de un siglo convulso. Se buscó, entonces, que el arte pudiera manifestar hasta los sentimientos más profundos de melancolía, dolor y desesperanza que habían originado los conflictos bélicos; así como su contraparte, el arte como distractor, como un escape de la depresión, una oportunidad de olvidar y sanar. Por lo tanto, se buscaba un arte más humano, en el sentido de que pudiera expresar al hombre en toda su complejidad, con todo su cinismo y con todas las contradicciones que lo había colocado en la situación en la que se encontraba: derrotado, pero dispuesto a seguir adelante. Todo ello se pretendió ver en las diversas expresiones artísticas a las que las sociedades estaban acostumbradas y si estas no cumplían con aquellos requisitos, entonces se indagaron nuevas formas, nuevos modos de hacer arte. Como lo señala el historiador de arte Ernst Gombrich:

El arte no empieza observando la realidad y tratando de ajustarse a ella; comienza construyendo "modelos mínimos" que se modifican gradualmente a la luz de la reacción del espectador hasta que se "ajustan" a la impresión que se desea. Desde este punto de vista, no hay duda de que las obras de arte han satisfecho efectivamente a generaciones sucesivas, que las abordaron con distintos requisitos, pero con el deseo de plasmar convincentemente la expresión humana (1997, p. 113).

Por lo que la obra de arte es una respuesta a las necesidades estéticas, sociales e históricas de las generaciones que las gestan. No podría ser de otro modo, puesto que aquel arte que no da respuesta a estas exigencias corre el peligro de desaparecer. Es así, que la danza teatral, desde finales del siglo XIX, pero sobre todo a principios del siglo XX, se va transfigurando, rebelándose contra aquella que se mantenía como la danza teatral y académica por excelencia: la danza clásica. Se rompió con los esquemas rígidos de su cuerpo técnico, en pro de una liberación expresiva y creativa que en sus inicios sobrevivió únicamente durante la vida de aquellos que la gestaron y desarrollaron, hasta que surgieron coreógrafos capaces de organizar un sistema técnico y estético apto para sobrevivir la espontaneidad del movimiento dancístico. De este modo, es que surgió la danza moderna y, posteriormente, la contemporánea, impugnación de lo que se consideraba arcaico y ajeno a la realidad estrepitosa del siglo XX.

El ballet visto como aquella lucha contra la gravedad, que procura mantener los cuerpos etéreos, ligeros, flotantes, ya no concuerda con la desilusión provocada por el derrumbamiento del progreso, en el que se tenía tanta confianza. Mas, no por ello, la danza clásica desapareció, pues contaba con un respaldo técnico, científico y artístico que ya había sobrevivido dos siglos. En realidad, procuró mantenerse a la vanguardia, principalmente a partir de Los Ballets Rusos 
de Diaghilev; pero su contraparte moderna, si bien no la opacó, compitió por el afecto de creadores, ejecutantes y espectadores.

Ninguno de estos dos géneros dancísticos logró vencer al otro, sino que consiguieron tolerarse e incluso paulatinamente comprenderse, hasta que aparecieron artistas que reconocieron lo mejor de cada uno. La fortaleza técnica y expresiva de la danza clásica, capaz de alcanzar el dominio total del cuerpo y, de esa manera, acceder a la amplia gama de movimientos que era posible desplegar con la emotividad contemporánea, la cual poseía un conjunto de propuestas técnicas más sólidas que conjugaban distintos tipos de preparación física y expresiva. Así, se da inicio a una fusión de géneros dancísticos que reveló a la danza clásica contemporánea como un nuevo estilo coreográfico que se mueve en armonía con las sociedades que lo ejecutan.

Como se ha podido apreciar, no se puede determinar un momento o una obra específica que marquen el inicio de este estilo coreográfico. El historiador del arte Serafín Moralejo señala que debe abandonarse aquella idea con la que se determinó que un estilo, y exclusivemante uno, abarcaba todo un periodo con características que eran afines a todos los aspectos estéticos y sociales de determinado momento:

Se vino a decir que el estilo era la época, en sentido y con implicaciones similares a como los prerrománticos establecieron que "el estilo es el hombre." Amplios periodos históricos, que engloban varios siglos, vinieron a ser así dotados de una especie de talante o fisonomía expresiva personal. Homogénea y unánime ... Por supuesto que la realidad histórica no se dejaba muchas veces "estilizar" tan fácilmente con los moldes contorneados de los supuestos estilos históricos, pero el totalitarismo tenía sus coartadas: relegar a la letra pequeña importantes manifestaciones artísticas por el mero hecho de que no encajaban en la unanimidad ideal que se había privilegiado como definitoria del periodo (2004, p. 117).

Un estilo artístico no puede definir por entero a todo un periodo histórico, su alcance estético-conceptual no es tal para que siga considerándose a los estilos como determinantes de todo un grupo social, en un espacio y tiempo específicos. Del mismo modo, no puede hablarse de cambios tajantes de estilo, puesto que incluso llegan a coexistir distintos estilos en un mismo tiempo y sociedad, obedeciendo, claramente, a las necesidades expresivas de las generaciones que lo gestan.

De esta manera, es importante considerar que el desarrollo de este estilo coreográfico, la danza clásica contemporánea, comenzó a gestarse con las creaciones coreográficas que realizaron Nijinsky y su hermana Nijinska a principios del siglo XX, con el rompimiento de líneas que la técnica de la danza clásica había determinado desde dos siglos antes (Abad, 2012, pp. 162-222). Lo mismo sucedió con otros de los integrantes de Los Ballets Rusos de Diaghilev que, una vez desintegrada la compañía, buscaron nuevas agrupaciones en donde se pudieran seguir expresando dancísticamente. Como fue Lifar en Francia, quién se adjudicó la creación de la danza neoclásica (Abad, 2012, pp. 264-271) y, en mayor 
medida, Balanchine en Estados Unidos, con la creación de ballets en los que buscó privilegiar a la danza por encima de las demás artes que le acompañaban, sin abandonar jamás el apoyo musical para sus creaciones coreográficas (Abad, 2012, pp. 301-323).

Esta manera de pensar con respecto a la danza también se desarrolló paralelamente en la danza moderna, ya que se da completo protagonismo al movimiento e incluso se omite cualquier acompañamiento musical para solamente apoyarse en ritmos percutidos o en el propio ritmo emanado del cuerpo del bailarín. Así, Mary Wigman y su "danza absoluta" se revela contra el ballet, no solo técnica y expresivamente, sino también para demostrar que la danza podía ser un arte independiente que no debía valerse de la música, la escenografía o el vestuario para expresar los sentimientos, ideas o conceptos que el coreógrafo y bailarín buscaban dar a conocer en un escenario. Este último ahora también se modificaba, puesto que el espacio dancístico no era necesariamente teatral, sino que se traspasaba a ambientes naturales, en el exterior; todo como parte de ese pensamiento liberador del cuerpo danzante (Au, 2012). La danza ahora podía ser ejecutada por cualquiera, o al menos eso se pretendía, puesto que encontraba su impulso en los movimientos cotidianos y personales de cada ejecutante.

No obstante, este tipo de movimiento, al ser tan personal, se perdió en los instantes de la danza o en lo efímero de las vidas de sus bailarines. Se necesitaba, entonces, un cuerpo técnico capaz de transmitir la esencia de los desplazamientos modernos a nuevas generaciones y así, permitir la supervivencia de la danza moderna de la manera en la que han sobrevivido las danzas desde tiempos antiguos: al ser ejecutadas una y otra vez por distintas generaciones. Aun cuando el descubrimiento cinematográfico ya permitía la conservación de la imagen de una ejecución dancística, no era posible que la danza se mantuviera viva, puesto que esta necesita revivir en cada interpretación, como único medio en el que este arte se manifiesta en esplendor (Dallal, 2007, pp. 40-42). No se trata de una mera repetición del movimiento, sino de la manifestación viva de los sentimientos, ideas, historias o conceptos que inspiran una obra dancística.

Es así que, comenzó a desarrollarse un corpus técnico que dio orden a los principios estéticos y expresivos de la danza moderna y que ya habían sido planteados por teóricos del movimiento como Delsarte, Delcroze o Laban (Alemany, 2012). Así, el torso como núcleo del movimiento se volvió fundamental para el desarrollo de una técnica de la danza, ahora denominada contemporánea, por tratarse de una disciplina dancística más actual, tanto por sus temáticas, como por las concepciones estéticas que se expusieron en los desplazamientos de los bailarines; tanto en escena, como en su preparación física y artística. La contracción y elongación no únicamente del torso, sino de las distintas extremidades del cuerpo, dio pie a una amplia gama de movimientos, que ahora también se ejecutaban en el piso, como manifestación de la humanidad del cuerpo. Es decir, de lo terrenal del hombre y de la mujer -quienes dejaban de ser hadas, silphydes, princesas o príncipes- que buscaban mantenerse ligeros, apenas tocando el piso, se buscó hacer evidente el peso del cuerpo y la fuerza de gravedad que se ejerce sobre él, como un medio de expresión dancística. 
Martha Graham fue un personaje fundamental en la historia de la danza contemporánea por su preocupación por desarrollar una técnica que permitiera la formación de bailarines contemporáneos (Au, 2012). Este interés le fue heredado a Merce Cunningham, quien buscó el perfeccionamiento de tal metodología; para lo que decidió retomar del ballet el fortalecimiento de las extremidades inferiores, sin abandonar los preceptos básicos de la danza contemporánea concentrados en la amplitud de desplazamientos del torso (Abad, 2012, pp. 366-377). Es así que este género dancístico comenzó a consolidar de distintas maneras su cuerpo técnico, algo muy característico de la danza contemporánea: la constante búsqueda de técnicas de preparación física y artística de sus bailarines. Lo anterior es de gran importancia, puesto que son estos principios básicos los que fueron retomados por los nuevos coreógrafos de agrupaciones de danza clásica, como recursos estéticos necesarios para expresar mediante sus obras su realidad, sin abandonar la tradición del ballet. Tal como lo hizo Maurice Bejart con su ballet de Lausanne o William Forsythe con la creación de ballets para distintas compañías de prestigio internacional y para su propia compañía, ya que como el mismo dijo: "el vocabulario clásico nunca será viejo. Es la manera de escribirlo lo que lo hace envejecer. Así que yo lo empleo para contar historias de hoy" (Abad, 2012, p. 425).

A su vez, la danza contemporánea en su asidua indagación de nuevas metodologías del movimiento dancístico, también reconoció en la técnica clásica un medio de preparación fundamental para el bailarín. No para controlarlo o adiestrarlo y manipularlo, sino para aprender a reconocer su cuerpo y cómo moldearlo. De modo que, los ejecutantes fueran capaces de expresarse en escenario con plena libertad, una libertad ahora otorgada por el completo dominio del cuerpo, que les permite concentrarse de manera más consciente en la interpretación artística del movimiento. No obstante, la danza clásica contemporánea es ejecutada principalmente, por bailarines cuya preparación es fundamentalmente clásica, pero también incluyen en su formación a la danza contemporánea. Mientras que los coreógrafos pueden ser surgidos de las filas del ballet y de la danza contemporánea. Cabe resaltar que este estilo se caracteriza por hacer notar la preparación clásica de los bailarines, pero enriquecida por su conocimiento consciente de la danza contemporánea, haciéndolos capaces de ejecutar secuencias dancísticas que conjugan ambas técnicas.

Creativamente, este estilo coreográfico se vincula más con lo propuesto por la danza moderna desde sus orígenes, en donde no necesariamente se narraba mediante los desplazamientos una historia, como en el ballet, sino que trata sobre ideas, sentimientos, conceptos o simplemente movimientos inspirados por el ritmo, ya sea musical, por percusión o emanado del mismo cuerpo: "danza absoluta". De este modo, por lo regular no se tiene mucho énfasis en la elaboración de una escenografía figurativa, sino que, en muchos casos, solamente se cuenta con un fondo negro que es modificado por medio de luces o por telones de un solo color; así 
como, utilería minimalista, en ocasiones intencionalmente introducida para que los bailarines interactúen con ella. Se trata entonces, de una armónica fusión de los principios estéticos de ambos géneros dancísticos con la finalidad de crear y ejecutar obras que, sin olvidarse de la tradición del ballet, pueden valerse de los movimientos más contemporáneos, para manifestarse lo más humanamente posible ante un público que así lo demanda.

\section{La danza clásica contemporánea en México}

Incluso cuando en México el ballet no despuntó a plenitud debido al contexto político, social y cultural del país desde su llegada a finales del siglo XVIII hasta la actualidad, los procesos más revolucionarios del siglo XX con respecto a la danza se desplegaron de manera notable. Muestra de ello fue el Movimiento de la Danza Moderna Mexicana (Dallal, 1996), con el que se introdujo un nuevo género dancístico que, como ya hemos visto, fue elemental para el surgimiento y consolidación de la danza clásica contemporánea. Si bien en México no surgió una técnica propia de la danza contemporánea, si se manifestó una originalidad creativa, mediante las temáticas nacionalistas que retomaron sus coreógrafos (Tortajada, 2002). Mientras que la adopción de técnicas ya más consolidadas como la Graham, permitió un despliegue creativo, que paulatinamente se fue desprendiendo del ámbito nacionalista y, al igual que en otros países, se valieron de las ideas, sentimientos, conceptos o movimientos que mejor sirvieran para la creación y ejecución de obras contemporáneas (Dallal, 1996).

Para el caso mexicano, los bailarines y coreógrafos de las filas clásicas fueron principalmente quienes buscaron nuevos modos de movimiento dancístico por medio del acercamiento a la expresividad contemporánea, sin que necesariamente se adoptara su técnica. Inevitablemente, esto fue necesario para que este tipo de creaciones dancísticas pudieran distinguirse del estilo neoclásico, el cual emplea en su totalidad una técnica clásica, pero cuyas temáticas son distintas a las del ballet tradicional y más cercanas al expresionismo contemporáneo, pero no necesariamente se lleva a cabo la ejecución de desplazamientos fundamentados en la técnica de la danza contemporánea.

Agrupaciones como el Taller Coreográfico de la UNAM, el Ballet Clásico de México -después denominado Compañía Nacional de Danza (CND) - entre otras compañías, principalmente asentadas en la capital del país, comenzaron a introducir en su repertorio obras de danza clásica contemporánea, aunque de manera más clara y evidente, en la última década del siglo XX. Actualmente, es un estilo que se ha esparcido por el país y prácticamente todas las compañías reconocidas nacionalmente cuentan dentro de su repertorio con obras de este estilo. Más recientemente, han surgido agrupaciones cuya línea estética está dedicada únicamente a la creación y ejecución de este estilo, como también ocurre en el resto del mundo. 
Por lo tanto, se trata de un estilo que ya es reconocido por los mismos creadores y ejecutantes, comúnmente denominado ballet contemporáneo, al cual se consideró pertinente denominar danza clásica contemporánea por el uso indistinto que se le da actualmente al término ballet. Esto no quiere decir que este sea un nombre determinativo; ya que, es el uso del término lo que, en ocasiones, provoca la asignación que se le da a un estilo o derivado del análisis histórico artístico que se presenta de manera posterior con respecto a un modo distinto de hacer arte. Debido a que la danza clásica contemporánea es una forma de creación y ejecución dancística que está en pleno desarrollo, los estudios que se realicen de esta, en el presente y, sobre todo en el futuro, determinarán de manera más precisa sus características estéticas y, por tanto, el término que mejor lo describa.

No se trata de un estilo coreográfico único puesto que, convive aún con el tradicional clásico, con el contemporáneo y demás estilos dancísticos que se vinculan estrechamente con el género que los produce; lo que no lo invalida, sino al contrario: "solo hay estilo, cuando hay posibilidad de opción, aun cuando esta se reduzca a la de desechar el no-estilo" (Moralejo, 2004, p. 199). De modo que, la convivencia de varios estilos exige mayor claridad en sus recursos estéticos, de manera que estos puedan ser diferenciados entre sí, reconocidos, aceptados y ejecutados. Sobre todo, en la danza que siempre conviven todos los géneros dancísticos, porque cada uno de ellos representa las distintas caras de las sociedades. Así como, las variadas facetas del ser humano, en su contemporaneidad y parte de su devenir histórico.

\section{Los elementos de la danza como herramientas analíticas}

La definición de un estilo coreográfico parte de un análisis histórico de sus transformaciones estéticas, evidentes en sus manifestaciones artísticas. Es por ello que el análisis formal de las obras dancísticas que pertenecen a dicho estilo coreográfico es esencial para completar la construcción conceptual que lo explica. Teniendo en cuenta la definición que Dallal ofrece de la danza, es posible entender que esta cuenta con elementos que pueden ser analizados: "el arte de la danza consiste en mover el cuerpo dominando y guardando una relación consistente con el espacio e impregnando de significación al acto o acción que los movimientos desatan" (2007, p. 20). Así, esta disciplina artística ha sido empleada por el hombre desde la antigüedad, valiéndose de su cuerpo como principal instrumento, para expresar a través del movimiento, necesariamente acompañado por el ritmo, sus realidades religiosas, psicológicas y recreativas; en otras palabras, sociales, en un espacio determinado.

La danza, además del cuerpo y el movimiento como materia prima, posee otros elementos que, al ser analizados por separado - hasta donde la obra dancística lo permita- y en conjunto, desentrañan el significado histórico y formal del ballet que se está estudiando. Dallal 
explica la importancia de cada elemento en la ejecución dancística y deja ver cómo cada uno mantiene relación con los demás, en mayor o menor medida, dependiendo del tipo de obra dancística que se esté observando. Pero que vistos en su totalidad dan sentido y significado a la obra, estrechamente vinculada con la sociedad y contexto que la genera.

Uno de los elementos de análisis, ya antes mencionado, es el cuerpo humano. A partir de cómo este es manipulado por los bailarines de acuerdo al contexto histórico y social al cual pertenecen, es la manera en que se ejecutará danza y se crearán obras dancísticas. Acontecimiento que, en la historia de la danza, y en todo proceso histórico, tiene que ver con "los contextos regionales, de ubicación, artísticos o sociales" (Layson, 2001, pp. 218-219), así como los estéticos, antropológicos, culturales, políticos, psicológicos y económicos. Por lo tanto, a través de este elemento se analizará el contexto en el momento de la representación de la obra Pájaro de Fuego ya que su análisis permite vislumbrar la manera en que el ballet mexicano percibe el cuerpo y su empleo para hacer arte, por medio de un entrenamiento físico, psicológico y artístico que deriva en la ejecución dancística

Otro elemento a considerar es el espacio. Resulta importante porque es en este donde el bailarín tiene la posibilidad de crear sus movimientos para lo que necesita una plena conciencia de él y de la relación con su cuerpo. Es por ello que el análisis de los límites y posibilidades que proporciona el escenario es esencial para el reconocer la influencia de este en el desenvolvimiento dancístico.

Ya que nos referimos a los movimientos del bailarín, cabe resaltar su importancia y su nexo con el cuerpo: ambos, como ya se dijo, constituyen la materia prima de la danza. Así pues, el movimiento de la danza específicamente, la danza clásica se encuentra dentro de las técnicas extracotidianas del cuerpo. Debido a que desempeña una función pública, es decir, que aun cuando el entrenamiento de un bailarín se lleva a cabo de manera personal, se prepara para presentar su trabajo frente a varios testigos: el público. De acuerdo con lo que establece el crítico de teatro y filósofo italiano Ugo Volli, a diferencia de las técnicas cotidianas, aquellas consideradas "normales", "naturales" o "simples" por cualquier cultura: saltar, comer, correr, parir, dormir, trepar, entre otras (2001, p. 83); las extracotidianas requieren de un aprendizaje formal, prolongado y realizado de manera periódica:

se produce con ellas una desviación considerable del uso "normal" del cuerpo, una alteración de los ritmos, de las posiciones, de la utilización de la energía, del dolor y de la fatiga ... siguen lógicas internas bastante precisas que reducen considerablemente el margen de arbitrariedad y con él la posibilidad de libres variantes. La palabra "técnica", referida a estas prácticas, no es utilizada a nivel de metáfora, alude ... a un saber hacer empírico que se basa en conocimientos generales pragmáticamente bien fundamentados (2001, p. 84). 
El ballet, entonces, consiste en una técnica extracotidiana pública y como tal, pretende llamar la atención del espectador. Asimismo, obedece a los vínculos de su cultura: a los códigos formales, éticos, estéticos, artísticos, políticos y sociales de la cultura que la genera, recrea o representa (Volli, 2001). Con base en esa técnica, el hombre le da significación al movimiento, pasando de un periodo de inmovilidad a otro, lo cual no quiere decir que dicha falta de movilidad necesariamente corresponda a una ausencia total de movimiento, sino que puede tratarse de una transición o preparación entre un movimiento y otro (Dallal, 2007), para así crear coreografías. En otras palabras, la construcción de estructuras de movimiento en el espacio, acompañadas de un ritmo y una lógica que obedece a la creatividad del artista.

El ritmo en la coreografía es incluido dentro del elemento tiempo y le brinda a la danza un apoyo para su ejecución. Este puede consistir únicamente en acentos producidos por algún instrumento de percusión o establecidos por el mismo movimiento dancístico, así como en un conjunto de sonidos y cadencias en un tiempo determinado que se conjugan con base en una metodología científica para dar lugar a melodías cargadas de significación: la música. Para el caso del ballet, desde sus orígenes y especialmente durante la época del surgimiento del estilo clásico, música y danza conviven de manera que, siempre se busca que el desenvolvimiento de ambas sea fluido y congruente. Por lo tanto, la música se convierte en un elemento esencial para la creación y ejecución dancística. La descripción de las distintas transiciones coreográficas de los bailarines de la CND, en el escenario principal del Palacio de Bellas Artes y su plena alianza con los ritmos y matices musicales, serán analizados por medio de los elementos espacio, tiempo y movimiento. En conjunto dan sentido a las obras y que, por lo tanto, no pueden ser estudiadas por separado.

La relación luz-oscuridad es un elemento que nos permite considerar al espacio, la iluminación, el vestuario y el maquillaje como los aspectos que, en conjunción con los otros elementos ya mencionados, permiten transmitir el mensaje completo que la obra pretende comunicar al espectador. Los "grados de luminosidad y la capacidad lumínica de las áreas espaciales en las que se realiza una danza puede tener consecuencias directas sobre la secuencia, el lapso o la forma dancística" (Dallal, 2007, p. 36) y lograrán que el espectador reconozca los distintos matices de la obra, contribuyendo así a una mejor comprensión del significado de la misma. La escenografía o ausencia de esta, el empleo de iluminación para matizar o enfatizar momentos coreográficos. Así como, el vestuario y maquillaje serán explicados desde el elemento relación luz-oscuridad, para demostrar cómo los cambios de luz y color acentúan la significación de las obras de manera que, el espectador pueda involucrarse con lo que observa.

La danza, al tratarse de un arte visual, depende de la forma para que su significación sea plenamente apreciada. De este modo, la apariencia de la danza está estrechamente vinculada con la relación luz-oscuridad. Sin embargo, para describir una secuencia dancística se deben 
referir todas las variaciones que va adquiriendo cada movimiento, es decir, que la forma implica cada posición del cuerpo y su relación con el espacio, así como la significación de cada paso dancístico (Dallal, 2007). Por lo tanto, para que una obra dancística tenga forma debe conjugar todos y cada uno de los elementos: cuerpo; espacio; movimiento y su significación; tiempo y la relación luz-oscuridad: precisamente así, el espectador será capaz de involucrarse con la obra que observa y podrá convertirse en participante.

Por medio de la descripción y estudio de los elementos esenciales de la danza que menciona Dallal, se realizará un análisis formal de las obras Pájaro de fuego, Mono Lisa y Alleman$d e$. Debido a que en ellas se encierra la esencia misma de esta disciplina artística y se trata de ballets que por sus características estéticas forma parte del estilo coreográfico de la danza clásica contemporánea. El análisis formal de las obras se realizará con la revisión exhaustiva del video de la función del día 24 de noviembre de 2014 en el Palacio de Bellas Artes, publicados en la página web de la Compañía Nacional de Danza y en su canal de youtube.

\section{El cuerpo y su contexto sociocultural en México}

El cuerpo como materia prima de la danza puede ser conducido de muy variadas formas para que la ejecución de movimientos dancísticos se mantenga acorde a las percepciones culturales de las sociedades que los realizan. El profesor de periodismo y comunicación audiovisual de la Universidad Carlos III de Madrid, Gérard Imbert, menciona que el cuerpo es un producto social condicionado por códigos y relaciones sociales que nos llevan a valernos de él como utensilio y en donde el Estado juega un papel crucial, al apropiárselo a través de las leyes, convirtiendo a la sociedad en un solo cuerpo, el cual manipula a su antojo y de acuerdo a sus intereses. Por tanto, la oposición al orden establecido y todas aquellas manifestaciones públicas o privadas, simples o artísticas, que se vinculan con dicha oposición, son un intento por recuperar una auténtica propiedad individual del cuerpo (2001). Probablemente, no se trate meramente de un intento, sino de una verdadera incautación del cuerpo. Puesto que, una vez que este es empleado metódica y conscientemente para su acondicionamiento físico y expresivo mediante técnicas dancísticas, el ser humano logra un completo dominio de él para ejecutar movimientos que manifiesten su percepción estética del entorno. Sobre todo, en aquellas danzas más contemporáneas, cuya temática responde a las exigencias sociales y artísticas no únicamente del que observa, sino también del que ejecuta. De acuerdo con esto, y considerando que el ser humano emplea el cuerpo para moverse y que el movimiento es la materia prima de la danza, no hay duda de la necesidad de estudiar el contexto:

Las danzas no se hacen por sí mismas, las hacen las personas. Estas a su vez son influidas por las sociedades en que viven. Por tanto, el estudio de la historia de la danza también debe incluir algún examen del ambiente social y cultural del que han surgido los estilos coreográficos 
... estudiar el modo en que la gente bailaba, normalmente involucra mucho estudio sobre su modo de pensar y de vivir (Anderson, 2001, p. 163).

Es a partir de las características naturales del cuerpo humano que se definen las capacidades actorales y fisiológicas para "hacer 'significativos' los movimientos en el espacio" (Dallal, 2007, p. 23) que se convierten en danza. La constitución física del hombre y de la mujer, así como, la forma en la que esta se emplea varía de acuerdo a factores culturales. Por lo que, cada comunidad, pueblo o nación, en correspondencia con su temporalidad y la visión que en ella se tenga de la corporalidad, desarrollan una cultura del cuerpo que se reflejará en la forma de hacer danza, que, al llevarse a un nivel profesional donde es posible presentarla en escenarios de todo el mundo, probablemente ampliaría el acervo cultural que contribuirá en una práctica de la danza más diversificada (Dallal, 2007). Esto explica cómo el ballet a pesar de ser un arte europeo, a lo largo de su historia, ha logrado expandirse en todo el mundo: por tratarse de una disciplina que, a través de su codificación y perfeccionamiento del cuerpo en movimiento, consigue preparar y moldear de manera estética el cuerpo humano para ser conducido artísticamente en distintos géneros dancísticos.

Por ello, es importante considerar cómo el cuerpo ha sido apreciado y manipulado en el contexto mexicano. Tal percepción fue drásticamente modificada tras el proceso de conquista en el siglo XVI, con la introducción de la religión católica a nuestro territorio. Proceso mediante el cual los cuerpos de los naturales fueron cubiertos con ropas de manta que ocultaron todas aquellas partes que, de acuerdo a la mentalidad católica, provocaban tentación y, por lo tanto, eran consideradas pecaminosas. De esta manera, el cuerpo de los naturales dejó detrás el taparrabo, para apropiarse de vestimentas que se asemejaron cada vez más a la moda europea, lo que repercutió inevitablemente en la manera de danzar. A pesar del inevitable mestizaje cultural, las danzas adoptadas durante el periodo virreinal se encontraron profundamente influenciadas de la cultura europea, particularmente la española, así como la africana y la nativa (Ramos, 1979). Aunque estas últimas se manifestaban de manera más esporádica ya que, en la naturaleza estética de sus movimientos, se veían meneos pecaminosos que no se consideraban apropiados por la sociedad y que, por lo tanto, fueron prohibidos.

Durante el primer siglo del México independiente, la situación no cambió de manera significativa. El decoro que debía mantenerse con el cuerpo, sus vestimentas y la manera de moverlo aún se veía influenciada fuertemente por un pensamiento conservador. En la danza sucedía de la misma manera, aquellas bailarinas que salían a escena con poca ropa o con faldas cortas o incluso con tutús - para el caso del ballet - no eran vistas con buenos ojos. Es hasta finales del siglo XIX y principios del XX que la percepción corporal comienza a modificarse. La idea de un acondicionamiento físico comienza a esparcirse de manera paulatina y bailarinas 
de la danza moderna se desprenden de los apretados corsés y las zapatillas, para bailar con túnicas holgadas y casi transparentes, por lo que son fuertemente criticadas (Tortajada, 2002). Mas son ellas quienes comienzan a marcar la pauta de una nueva impresión del cuerpo. La reforma educativa de José Vasconcelos justificó en la preparación física uno de los modos para fortalecer la raza mexicana:

La creación de un Departamento de Educación física en 1922 bajo sus auspicios dio lugar a un sinfín de manifestaciones deportivas, bailes masivos, orfeones gigantescos, festivales y desfiles de hombres "hercúleamente" constituidos, hombres que, según declaración de la Secretaría de Educación Pública, "cimentarán, sin duda alguna, una generación próxima, que no desfallecerá bajo los rayos del sol ni sentirá flaquear sus miembros por algunos minutos de esfuerzo corporal" (Bidault, 2002, p. 653).

Es así, que la cultura física se convirtió en una herramienta fortalecedora del carácter nacional. En ese momento el cuerpo debía procurarse, cuidarse, mantenerse sano y limpio. Ideas que, con la entrada de la modernidad y de la introducción del vidrio y la electricidad, incrustaron en el subconsciente social la noción de transparencia, de luminosidad, de higiene que se reflejó en el cuerpo y en la manera en que ahora se hacía uso de él. "El interés repentino por la gimnasia y los deportes era el resultado de una nueva forma de esnobismo entre la burguesía de fin de siglo" (Bidault, 2002, p. 653) que se vio respaldada y prolongada por el pensamiento de Vasconcelos.

No obstante, las reglas y códigos conservadores a los que se veía atada la percepción corporal y, por lo tanto, dancística no se desvanecieron con la introducción de la Gimnasia y la Educación física en las escuelas. Aún las bailarinas de la danza moderna que mostraban en sus movimientos sus piernas desnudas bajo faldas largas y holgadas eran causa de controversia. Sin embrago, su adherencia a la temática nacionalista latente de la época, así como, el auge de la cultura física permitió que su popularidad aumentara y, paulatinamente, fueran reconocidas junto con aquellos coreógrafos y bailarines que las acompañaron como parte de una tendencia reconocida internacionalmente: el Movimiento de la Danza Moderna Mexicana.

El cuerpo danzante en el contexto mexicano tardó en desprenderse de sus imágenes más recatadas. Las representaciones de ballet en las que los príncipes y princesas se desplazaban en el escenario, ya no eran mal vistas. Es por ello que las temáticas más emblemáticas de los ballets como la ilusión de ligereza y fragilidad de las bailarinas rescatadas por los caballerosos y valientes príncipes fue la principal oposición de la danza moderna y contemporánea. Esto -además de lo temático- buscó, técnicamente, contraponerse a lo ya establecido por la danza académica, mediante el rompimiento de líneas en todas las extremidades del cuerpo; las contracciones del torso y el aprovechamiento del peso corporal para ejecutar movimientos a ras de piso. Sin embargo, eran desplazamientos considerados antiestéticos por una sociedad conservadora, en la que el género masculino y 
femenino poseían un papel específico que era reforzado por el cine y la televisión.

La danza moderna pugnó, en sus inicios, por una liberación femenina y después por una igualdad estética entre géneros, a través de la introducción de pas de deux o pas de trois solo de hombres o de mujeres, procurando así que los movimientos ejecutados por uno u otro género fuesen los mismos. Hecho que, posteriormente, fue retomado por la danza clásica en sus coreografías neoclásicas y contemporáneas. La búsqueda de una uniformidad artística en los bailarines también se manifestó en el vestuario, al desarrollar los mismos diseños tanto para las féminas como para los varones, con la única diferencia de las zapatillas; puesto que, las primeras siguieron utilizando "puntas" y los segundos zapatillas suaves o de media punta.

Actualmente, la danza clásica contemporánea exige la misma capacidad técnica y artística en sus bailarines y bailarinas. Sin embargo, existe un obstáculo que restringe la difusión y aceptación de la danza como una profesión digna de la cual se puede subsistir. Esto es, en parte, consecuencia de la percepción social que considera homosexuales a los bailarines, principalmente aquellos dedicados a la danza clásica. No obstante, tal idea puede extenderse casi a cualquier género dancístico con la mera aseveración "soy bailarín". En la sociedad mexicana aún se mantiene una lucha entre quienes mantienen una ideología conservadora y ven en la homosexualidad uno de los motores que echa a andar una sociedad corrupta y viciosa; contra aquellos que defienden la manera en que expresan su sexualidad e impugnan por los derechos que les han sido restringidos por considerarlos algo antinatural o desafortunado, lo que impide el desarrollo y consolidación de una honesta comunidad social. Como si la complejidad que entreteje a una sociedad y que, ligada a su contexto y a su relación con otras sociedades, pudiera reducirse a la controversia que desata la orientación sexual. De este modo, ser considerado homosexual en México aún puede ser una limitante para que los varones vean en la danza una profesión tan válida como cualquier otra. Lo que aunado a la deficiente educación artística que reciben los niños y el insuficiente apoyo gubernamental para las artes y la cultura desemboca en un reducido número de individuos que deciden dedicarse a este arte.

Afortunadamente, el prejuicio de la homosexualidad, al menos por el lado de los ejecutantes, se ha difuminado y, pese a la insuficiente difusión que aún ancla a la danza en México, niños y jóvenes continúan integrándose al gremio dancístico para interpretar piezas contemporáneas y de danza clásica contemporánea, sin temor a la censura. Sobre todo, en las metrópolis más grandes y pobladas del país, cuyo soporte económico estatal les ha permitido fundar una compañía de danza estable. Mientras que, en las provincias o pueblos más pequeños es preocupante que aún permee, de manera latente, la acusación de homosexualidad para el género masculino dedicado a bailar e incluso el desconocimiento casi total de lo que realmente significa bailar profesionalmente. Es por ello que algunas ciudades han emprendido medidas 
para incentivar la integración de nuevos individuos al ambiente dancístico, sobre todo del género masculino. Así, en la Cuidad de México y Monterrey se implementaron en sus escuelas de danza programas especiales para varones, permitiéndoles aplicar para el ingreso a una edad que, para el estudio profesional de la danza es considerado tardío, pero es el momento en el que aquellos sujetos que de verdad buscan formarse como ejecutantes dancísticos en una sociedad que los tacha de gays tienen la madurez y fortaleza para desafiar lo "tradicional".

Aún queda mucho por hacer para que la cultura sea apreciada, apoyada e impulsada en México. Por ende, la danza aún tiene carencias que no la han dejado despuntar como en otros países. No obstante, se ha luchado por mantener un desarrollo técnico, estético y artístico casi a la par del resto del mundo. En donde el desenvolvimiento dancístico no se encuentra tan condicionado por prejuicios sociales o menguado por la indiferencia social e institucional. Al menos en aquellos territorios en los que la danza profesional se desarrolló desde hace siglos, como Francia e Italia y otros en los que las artes recibieron un importante apoyo, como Estados Unidos, Alemania, Inglaterra, Rusia, Canadá o Cuba, por mencionar algunos. Países en los que las distintas manifestaciones dancísticas presentan una amplia gama de propuestas creativas, entre las que se encuentra el ya aceptado y ejecutado estilo coreográfico de la danza clásica contemporánea.

\section{Pájaro de Fuego, coreografía de Maurice Bejart, música de Igor Stravinski}

El ballet Pájaro de Fuego fue estrenado en el Palacio de los Deportes de París el 31 de octubre de 1970 (Béjart Ballet Lausanne, s.f.). Debido a que Maurice Béjart siempre buscó que algunas de sus obras fueran presentadas en espacios públicos para poder ser apreciadas por un amplio número de espectadores y, de este modo, difundir su trabajo y a la danza misma (Abad, 2012, p. 275). Labor por la que recibió el Premio Erasmus en 1974, que también se encuentra estrechamente relacionada con la percepción de los maestros, coreógrafos y bailarines de la danza moderna y contemporánea, que sacaron a la danza de los teatros para trasladarla a espacios abiertos más accesibles a un público diverso.

Fue representada nuevamente en México por el maître y subdirector artístico del Béjart Ballet de Lausanne, Julio Arozarena, para la función de gala en el Palacio de Bellas Artes de la Ciudad de México, por el festejo del 50 aniversario de la CND el 24 de noviembre de 2013 (Palapa, 24 de noviembre de 2013). En esta obra, se retoma el mito del ave Fénix encarnado en el Pájaro de fuego, quien se revela al ser despojado de su vestimenta, para dejarse ver en un unitardo rojo, mientras que el resto de los bailarines, permanecen ataviados con un uniforme que recuerda a los soldados de la Revolución Rusa y China. Según lo señala Béjart, en la nota de programa de este ballet, se trata del ave fénix que renace de entre las cenizas de la revolución, 
vista desde una perspectiva abstracta, puesto que el coreógrafo no pretendió representar el argumento original de la obra, ni mucho menos crear uno nuevo; sino dar énfasis a los movimientos rítmicos y melódicos de la composición de Stravisnky. A quién, además, consideraba un revolucionario (Béjart Ballet Lausanne, s.f.) por la manera en que construyó sus obras, con las disonancias derivadas del dodecafonismo y los acentos musicales sincopados que le caracterizan y que en sus inicios provocaron el rechazo de una parte del público.

Béjart retomó, únicamente, la Suite Orquestal del ballet del Pájaro de Fuego de Stravinsky, basado en una de las entrevistas que este tiene con Craft director de orquesta, que es contratado por Stravinsky en las últimas décadas de su vida como su asistente. Además, recopiló diálogos, entrevistas, memorias y conversaciones que se dieron a conocer en distintas publicaciones y que fueron reunidos en el libro Igor Stravisky y Robert Craft (Fernández, 2013). Y en la que señala la preferencia de esta versión, por encima de la del ballet completo. De esta manera, el coreógrafo representa dancísticamente la idea abstracta de revolución, con el tinte político que refiere el vestuario y el matiz artístico que proporciona la música de Stravinsky, como el mismo lo explica:

Yo había comprado un libro: 4 Poetas de la revolución (Blok, Essenin, Maiakovski, Pasternak). “iNuestros pechos son los metales que estallan!” exclamaba Maiakovski, ... Y si yo escuchaba la música, y solamente la música, sentía esa misma compulsión la misma ternura, las mismas esperanzas. Escuchaba a Stravinsky músico ruso y músico revolucionario. En el fondo, siempre es suficiente tomar la obra misma y si esta obra es fuerte, pronto se reconoce esa fuerza; la fuerza es contagiosa. ... cuando un coreógrafo se ocupa de una partitura solo la partitura puede guiarlo.... Y sobre esta partitura hay que incorporar las emociones modernas, contemporáneas. (Béjart, 1982, pp. 71-72)

Es por ello que Béjart justifica muchas de sus coreografías en la inspiración que le provocan las piezas musicales que selecciona para la elaboración de una obra dancística. O viceversa, la música lo guía para la construcción de coreografías que representen las ideas, sentimientos, emociones e imágenes que surgen de las notas y los ritmos que componen una melodía. Esta representación del Pájaro de fuego, como ave Fénix que renace de las cenizas y se manifiesta revolucionariamente como un poeta del movimiento (Béjart Ballet Lausanne, s.f.), se rodea de militantes que se mezclan armoniosamente con los acordes y secuencias métricas de la composición de Stravinsky. Culmina con una manifestación conjunta de unión ante la esperanza revolucionaria, cuando a los uniformados se les une un grupo de bailarines vestidos del mismo modo que los solistas, inspirados por los movimientos vertiginosos y elegantes del Pájaro de fuego - portador del espíritu de la Revolución- emprenden el vuelo hacia la libertad. 


\section{Relación luz-oscuridad}

La escenografía fue formada de manera abstracta y dinámica por el vestuario y los movimientos dancísticos de los bailarines, por los cambios y contrastes de las luces que matizan, y dieron énfasis a momentos claves de la obra: como la aparición del pájaro de fuego, su muerte, su renacer y la trasformación de los bailarines, que cambian su uniforme gris por un unitardo rojo, igual al que porta el Pájaro de fuego. Centraron, así, la atención del espectador en el movimiento, principalmente dancístico, pero enriquecido por la música y la relación luz oscuridad. De esta manera, dicha relación se desarrolla a lo largo del ballet, sin la necesidad de una escenografía figurativa o de vestuarios ostentosos, tal como se hizo en las grandes producciones de ballets clásicos, sino como lo propuso desde sus inicios la danza moderna y se reafirmó con la danza contemporánea. Así como la austeridad buscada por coreógrafos clásicos como Balanchine, Tudor y Aston en sus coreografías más expresivas. Se privilegia a la danza como movimiento puro, que se ve nutrido por la música que le inspira y le acompaña, al igual que los matices de luminosidad y penumbra que completan el lenguaje simbólico gestado, primeramente, en la coreografía, para ser transmitido por los bailarines y asimilado por el espectador, de manera que, este pueda ser partícipe de la obra.

\section{Coreografía, espacio, música y movimiento}

Los desplazamientos dancísticos estructurados por Bejart se desarrollaron con óptima musicalidad y coherencia en el escenario del Teatro de Bellas Artes de la Ciudad de México. Aun cuando se trata de una coreografía que originalmente fue presentada en un espacio abierto, su representación en teatros no modifica su composición original o significado. Los movimientos ejecutados dejan ver claramente la formación clásica de los bailarines ${ }^{1}$, pero se ven enriquecidos por pasos más contemporáneos como las contracciones de torso y extremidades, que rompen con las líneas clásicas académicamente establecidas, y la realización de secuencias de piso, también características de la técnica contemporánea, al explotar la gravedad natural del cuerpo hacia el piso. La interpretación del personaje del Pájaro de fuego está reforzada por el empleo de movimientos de brazos que procuran asemejarse a los realizados por un ave, razón misma por la que hace saltos ágiles y vertiginosos. Mientras que el cuerpo de baile alterna o ejecuta simultáneamente, secuencias coreográficas que asemejan algunos de los movimientos del solista, quien los va guiando e inspirando hacia la emancipación, la esperanza y la libertad, sobre todo conforme la obra se encuentra en su clímax y final.

1 Aun cuando las bailarinas no usen zapatillas de punta, sino suaves o de media punta, al igual que los hombres. 


\section{Mono Lisa, coreografía y música de Itzik Galili}

Se trata de un pas de deux $x^{2}$ estrenado en Stuttgart, Alemania en 2003. Mientras que la presentación mexicana la realizó Elizabeth Gibiat, asistente del coreógrafo Itzik Galili (Palapa, 24 de noviembre de 2013), quien es un coreógrafo israelí, cuya formación la realizó en el Reino Unido, su trayectoria le valió premios de coreografía y en 2009 fue cofundador y Director Artístico de la Compañía de Danza Contemporánea de Ámsterdam hasta finales de 2010. En adelante ha sido coreógrafo invitado en distintas compañías de danza internacionales, como Stuttgart Ballet, Ballets de Monte Carlo, Bayerisches Staatsoper Munich, Rambert Dance Company, National Dance Company, Staasballet Berlin, English National, entre otros (Dance Consortium. International dance across the UK, s.f.).

Desde la perspectiva del espectador, tal obra podría catalogarse como abstracta, puesto que no narra una historia figurativamente. Mas, el propio coreógrafo Itzik Galili no está de acuerdo con tal aseveración y afirma, en una entrevista realizada por Anabel Poveda para la revista Por la danza, "algunas veces lo abstracto es falta de conocimiento ... Que lo abstracto se convierte en tendencia quiere decir que nos olvidamos de buscar en profundidad el porqué, el origen y la causa de las cosas" (2006).

De acuerdo con esto, para Galili su inspiración proviene de lo personal, de aquellas experiencias que en determinado momento le motivaron a crear una coreografía específica y, como resulta común para los creadores, es un proceso que no siempre pueden definir con precisión: "yo tendría que pasar por quince años de tratamiento psiquiátrico profundo para poder darle respuestas específicas y más detalles, y quizás no serían las respuestas que usted quisiera. Yo no le voy a dar ninguna respuesta 'intelectual"' (Galili, 2006). Por lo que, para este coreógrafo, lo abstracto se ha empleado para designar aquello que no es fácilmente descifrable.

Incluso, él señala que tal incomprensión puede trasladarse al mismo creador, cuando este ha olvidado, después de un tiempo, todos y cada uno de los sentimientos, experiencias o motivos de su inspiración. Pero ello no quiere decir que tales musas desaparezcan de la obra y por eso sea ininteligible para el público. Los movimientos que configuran a la coreografía siempre emanarán un significado inherente a su forma, que se complementará por la interpretación del bailarín impregnándola con su personalidad, a su vez que la percepción del espectador de todo ello también enriquecerá su contenido. Así, el término abstracto realmente refiere a que, aunque el sentido del ballet no se muestre explícitamente, por medio de alguna representación figurativa o de una explicación escrita; mediante una sinopsis, se encuentra en los movimientos dancísticos que lo componen y que son asimilados por el bailarín y por el público de manera distinta. Lo que puede coincidir o no con lo que inspiró al coreógrafo. De ahí la importancia de

2 Término en francés que significa paso a dos y se trata de una coreografía que es ejecutada por dos bailarines 
dejar que la obra artística hable por sí misma, a través de sus características estéticas, ya que esta puede decir más, que lo que el autor pueda argumentar sobre ella.

\section{Relación luz-oscuridad}

El telón de fondo es negro y así permanece durante todo el pas de deux. Por su parte, la iluminación proviene casi siempre de la batería que se encuentra sobre el escenario o de las luces ubicadas tras bambalinas. Cuando se abre el telón, la batería visible en el escenario ${ }^{3}$, proyecta una tonalidad blanca y junto con los primeros sonidos de la pieza. Estas comienzan a subir hasta que desaparecen del campo visual del espectador. Al menos, al principio de la pieza, cuando las luces se encuentran en su punto más bajo, el proscenio ${ }^{4}$ permanece prácticamente en penumbra; de modo que, los movimientos ejecutados por los intérpretes son apreciados únicamente con su silueta enmarcada por la iluminación posterior. Una vez que la batería alcanzó su altura máxima, la luminosidad en el escenario se incrementa, incluyendo la del proscenio y permanece blanca durante todo el ballet. El vestuario es similar para ambos bailarines, llevan un short de licra color vino y una playera, también de licra. Para el hombre es de color vino con manchas terracotas en los brazos, para ella es toda de color terracota. Nuevamente la austeridad en escenografía y vestuario concentra la atención del público en el movimiento dancístico.

\section{Coreografía, espacio, música y movimiento}

Los primeros sonidos que acompañan a la coreografía son producidos probablemente por un xilófono o tal vez generados mediante un sintetizador, puesto que también se escuchan sonidos de rasgado de algún objeto y del golpeteo de una máquina de escribir, posteriormente. No son precisamente melódicos, puesto que provienen de instrumentos poco convencionales para la ejecución musical y más bien se asemejan a percusiones que marcan un ritmo. En esta coreografía se hace más evidente la formación clásica de la bailarina, por el uso de zapatillas de punta. No obstante, el hombre también manifiesta un dominio corporal derivado de esta técnica. Los desplazamientos dancísticos nuevamente se ven enriquecidos por movimientos emanados de la técnica de la danza contemporánea, como contracciones, posiciones fuera de centro, el "descuadrado" ${ }^{5}$ de las extremidades y el torso, el empleo de posiciones en dedans o

3 Normalmente las luces de la batería que se encuentra sobre el escenario, no están visibles y solo los cambios de luz son apreciados por la audiencia durante la ejecución de los ballets.

4 Parte más "baja” del escenario, aquella más cercana al público, justo a la orilla del tableado

5 Se refiere al rompimiento de la línea fijada en la técnica del ballet, que señala que el torso debe "dibujar" imaginariamente un cuadrado, que va desde los hombros hasta la cadera, cuando alguna parte del 
hacia adentro 6 , las cargadas de tipo acrobático 7 , el caminado casual o incluso "masculino" que ejecuta la bailarina ${ }^{8}$ y que se desprende de un movimiento cotidiano que, como ya hemos visto, se trató de una búsqueda fundamental de la danza moderna y, posteriormente, heredada a la danza contemporánea.

La interpretación de los ejecutantes va encaminada a la caracterización de dos bailarines, que hacen movimientos dancísticos inspirados en los ritmos marcados por diversos objetos. Ambos procuran realizar sus mejores pasos, como una constante competencia, algo que no es marcado de forma continua en la coreografía. Sí se hace más evidente en los momentos de descanso, en el que los bailarines intercambian una breve mirada retadora o realizan algún desplante que hace alarde de lo que han realizado.

El final de la coreografía está anticipado únicamente por una breve preparación de la cargada final, en la que la bailarina queda en un arco, apoyando sus glúteos y su espalda baja en los pies del bailarín, quién recostado en el piso, con los pies levantados en un ángulo recto, sostiene a su compañera; todo esto marcado por un acento final, ejecutado por el mismo sonido de xilófono que dio inicio a la obra. Posterior a esto, se hace un oscuro total que da por concluido el pas de deux. Si bien, el inicio de la coreografía está marcado por el solo del bailarín, no existe un clímax como tal. Aun cuando el principal desarrollo coreográfico se encuentra en el pas de deux, mantiene un ritmo estético e interpretativo constante, con breves descansos tanto dancísticos como de sonidos, para concluir casi de manera súbita.

\section{Allemande coreografía de Joshua Beamish, música de Johann Sebastian Bach}

Es un ballet que se estrenó en el Teatro Joyce Soho, en Nueva York el 17 de marzo del 2011, cuya música está compuesta por extractos de las Suites para cello de Johann Sebastian

cuerpo hace que los hombros, cintura y cadera salgan de este cuadrado imaginario, se le denomina una pose o movimiento descuadrado.

6 Rompe con la estética de la danza clásica, la cual emplea posiciones de los pies y piernas en rotación hacia afuera.

7 Comienzan a ejecutarse dentro de la danza clásica en Rusia con los ballets creados y ejecutados durante el periodo soviético y que son retomadas también por otros coreógrafos como Balanchine. Más comúnmente utilizados en el apogeo de la danza contemporánea y de ahí haciéndose cada vez más populares en ambos géneros dancísticos.

8 En el ballet el caminado de las bailarinas debe ser siempre por relevé (sobre el metatarso y con los talones levantados). Por su parte los hombres sí tienen momentos en lo que pueden caminar apoyando toda la planta del pie, siempre y cuando se trate de un paso elegante. 
Bach (MoveTheCompany, 2011). La representación que realizó la CND de las nueve danzas que comprenden esta obra, fue hecha por el mismo Joshua Beamish e incluyen solos, pas de deux, pas de trois, pas de quatre o pas de six. Asimismo, hay momentos coreográficos en los que participan doce bailarines.

Beamish es un coreógrafo canadiense que comenzó su formación dancística gracias a su mamá, maestra de danza que inculcó en su hijo el gusto por bailar, introduciéndolo a tomar primero clases de tap; después de ballet, jazz, danza ucraniana, teatro musical, danza contemporánea y hip-hop para, finalmente, inclinarse más por el ballet y la danza contemporánea (Ludden, 2014). Este acercamiento a diversos géneros dancísticos le permitió ampliar su perspectiva del movimiento y, así, explorar, primero, de manera personal mediante la improvisación un modo propio de bailar. A la vez, su variada formación dancística se ve latente en sus creaciones y cabe mencionar que algunos de los movimientos de brazos realizados en su coreografía Allemande, evocan ciertos desplazamientos empleados en el hip-hop. A su corta edad -28 años- ha logrado posicionarse como un creador reconocido y por ello ha tenido la oportunidad de trabajar para distintas compañías como The Royal Ballet, New York City Ballet, The Ashley Bouder Project, Pacific Northwest Ballet, Martha Graham Company, The National Ballet of Canada's YOUdance, CND de México, Cape Dance Company South Africa, el Royal Winnipeg Ballet, Toronto Dance Theatre, Ballet Kelowna, Santa Barbara Dance Theater, The Juilliard School, entre otros (MoveTheCompany, 2011).

Su proceso creativo, como él mismo afirma, parte de impulsos e instintos kinésicos, que son inspirados por la música. Transmite su sensibilidad por medio del movimiento dancístico y confiando en las similitudes que como género humano compartimos, observa lo interpretado por los bailarines de acuerdo a lo que él les ha explicado y, posteriormente, da orden y forma a la coreografía (Ludden, 2014). Esto es evidente en Allemande, ya que los movimientos expuestos son inspirados, principalmente, por el ritmo musical. Pero, además, el tiempo coreográfico es definido por la fluidez que se busca en cada desplazamiento y la conexión entre uno y otro, lo que será una constante en toda la obra y mantendrá unido cada paso y cada danza que la componen.

\section{Relación luz oscuridad}

El vestuario para las mujeres es un short ajustado de color azul marino, con una blusa de encaje, que tal vez sea un leotardo que permanece sujeto debajo del short, cuyo color varía entre azul marino, vino y beige, para cada bailarina. Los hombres utilizan un pantalón corto, hasta la rodilla, color gris y una camisa de un tono de gris más claro; otros, al contrario, un pantalón claro, con una camisa más oscura, con detalles en negro y blanco en las orillas. Por su 
parte, el tono de la iluminación es neutro o blanco y permanece así durante toda la obra, puesto que los matices de luz están marcados por el lugar del que provenga, no por el cambio de tonalidades en las luces. Hay momentos en que el escenario se llena de luz principalmente, cuando todo el cuerpo de baile aparece en escena. El telón de fondo es negro, sin ningún tipo de trazo, al igual que en las dos obras anteriores, centrando la atención en la danza y su fiel compañera, la música.

\section{Coreografía, espacio, música y movimiento}

Allemande es un ballet inspirado en la música de época barroca compuesta por Bach, pensada originalmente para ser ejecutada únicamente por cello. Sin embargo, cada vez se ha vuelto más común la utilización de música de concierto o que no fue creada para bailar, para la creación de coreografías con estructuras de movimiento muy diversas, así como para distintos géneros dancísticos. Para el caso del ballet, Mikhail Fokine fue el primero en emplear este tipo de música para sus creaciones coreográficas a principios del siglo XX. En tanto que, para la danza moderna y contemporánea su uso fue fundamental desde sus inicios, también en las primeras décadas del siglo pasado, con Isadora Duncan, para demostrar que su estética de movimiento podía emplearse con cualquier tipo de música o incluso sin ella. Ambas aportaciones contribuyeron para que, en la fusión de danza clásica con danza contemporánea, la amplia gama de movimientos a disposición de los creadores se explotara en la realización de coreografías como la de Joshua Beamish.

Así, Beamish intercala un movimiento fluido, con uno rápido o cortado y busca que no pierdan su carácter. Además de conservar su conexión "orgánica", es decir que cada movimiento está pensado para fluir de manera congruente con el ritmo que emana tanto de la música como de la coreografía misma. Una vez más, se privilegia el desplazamiento dancístico por sobre la escenografía, la iluminación o el vestuario; puesto que éstos operan, únicamente, en función de la danza, para resaltarla, matizarla y darle todo el protagonismo que busca el coreógrafo y ejecuta el bailarín.

A veces, tales desplazamientos se contraponen al ritmo musical, puesto que, si se trata de un adagio, algunos de los pasos ejecutados en esa pieza podían ser acelerados; o bien, en un allegro, simplemente, caminan los bailarines pausadamente por el escenario, lo que parece oponerse a la melodía, pero no así con el tiempo coreográfico. De manera que, no resultaban asincrónicos a la música y a la forma total de la obra, pensada así por el coreógrafo. Tal combinación de ritmos, tanto musicales como dancísticos, enriquecen la coreografía y evitan que se vuelva monótona. Hay un inicio, el primer fragmento, en el que se presenta la estética de la obra y que permanecerá en cada una de las danzas, pero no existe un clímax al que le siga una coda final. Es una secuencia de danzas con ritmos contrapuestos intercalados, unidas por la cadencia musical del cello, que compuso Johann Sebastian Bach e inspiraron a Joshua Beamish a crear Allemade. 


\section{Conclusiones}

La danza clásica contemporánea es un estilo coreográfico que comenzó a definirse con las transformaciones estéticas de la danza desde principios del siglo XX. Con el surgimiento de la danza moderna y lo que esta inspiró en los coreógrafos y bailarines clásicos para incluir en sus obras y, posteriormente, en el entrenamiento de los bailarines parte de la metodología de la danza contemporánea. Así como la parte creativa que esta nueva propuesta dancística siempre defendió: "la danza absoluta" y con lo que logró su protagonismo e independencia de otras disciplinas artísticas que hasta el momento habían hecho del ballet un gran espectáculo teatral, en el que la danza se acompañaba de una gran producción escenográfica y de vestuario, lo que, en algunos casos, opacaba al arte que las había unido: la danza misma.

La danza clásica contemporánea ha logrado un buen recibimiento por parte del público, ya que combina el perfeccionamiento corporal y expresivo del ballet o danza clásica con la versatilidad de la danza contemporánea y su amplio rango de movimiento conectado a la contracción y estiramiento del torso y las extremidades. Su temática, por lo regular, no es narrativa y puede considerarse un concepto, una idea o, únicamente, el ritmo de la música que acompañan y dan forma a la coreografía. Su escenografía, si es que la hay, tampoco será figurativa, frecuentemente, el telón desaparece o, si se usa, lo que puede estar plasmado en este será abstracto o en algún color neutro que pueda ser matizado por la iluminación. El vestuario también será austero, para brindar la mayor libertad de movimiento a los bailarines y acorde a la temática, escenografía e iluminación que el coreógrafo haya elegido.

El término asignado a este estilo coreográfico es la fusión de los nombres de los géneros dancísticos que lo configuran: danza clásica y danza contemporánea, aunque comúnmente es mejor conocido como ballet contemporáneo, sin embargo, el uso que se le da a la palabra ballet es diverso y va desde el nombre propio de una agrupación, o de una obra, hasta el de la técnica misma. Por ello, la conveniencia de denominarle danza clásica contemporánea, ya que el término danza clásica, al menos en México, es vinculado de manera más directa con la disciplina dancística del ballet. Por su parte, el término contemporánea tiene dos connotaciones, la primera, es su relación directa con la técnica de la danza contemporánea y, la segunda, con la temporalidad del estilo. Debido a que, se trata de un modo de crear y de interpretar la danza cuyos inicios son recientes y que podrían datarse del último tercio del siglo XX. Sin embargo, es en el siglo XXI que distintas compañías del mundo introducen en su programación obras con las características técnicas y estéticas de la danza clásica contemporánea y, actualmente, todas las compañías del mundo, incluso las consideradas más tradicionalistas, como las rusas, poseen dentro de su repertorio una o varias coreografías del estilo y son estrenadas en cada temporada. 
Las obras analizadas en esta investigación pertenecen a una temporalidad distinta de este mismo estilo coreográfico. El primer ballet es de sus inicios y los dos siguientes corresponden al periodo que podría considerarse de su apogeo. Así, en primer lugar, se tiene a Pájaro de fuego de Maurice Béjart, estrenado en 1970 en París, una obra en la que ya no se trató de narrar una historia, el coreógrafo se centró en el concepto de Revolución y lo traspuso en el personaje del Pájaro de fuego y en la misma música de Stravinsky. La coreografía incluye movimientos de danza clásica y de danza contemporánea, como algunas secuencias de piso y de contracción y elongación. Los distintos ritmos y matices coreográficos son acentuados con la iluminación, con lo que puede percibirse un inicio, un clímax y un final. Se trata, entonces, de una obra de danza clásica contemporánea que se basó en un concepto específico vinculado con todos los elementos que la complementan, creando así una forma que el público es capaz de asimilar, siendo partícipe de la misma.

En segundo lugar, Mono Lisa y Allemande son coreografías similares, en el sentido de que su inspiración principal es el movimiento y su unión con la música. Por un lado, Itzik Galili, en el 2003, desarrolló su coreografía, principalmente, en los sonidos y ritmos editados por él. Mientras que, por otro lado, Joshua Beamish, en el 2011, lo hace con composiciones de suites para cello de Bach. Sin embargo, en ambos, no es perceptible un concepto o ideas específicos que guíen la coreografía, sino más bien es danza pura que se mueve con un ritmo que determina ella misma. Es decir, que se ve fluido y en unión óptima con los sonidos que le acompañan. Lo esencial son los movimientos ligados entre sí; de grandes extensiones y fuerza para los bailarines; con desplazamientos acentuados, por lo regular precipitados; y con varias posiciones descuadradas o fuera de centro. Estos rompen con las líneas tradicionales del ballet, pero que, por su dificultad requieren de un buen control corporal, aspectos que los intérpretes obtuvieron con su preparación en danza clásica y danza contemporánea. No hay escenografía y la iluminación tiene algunos contrastes que matizan y dinamizan el sentido de las obras. Son ballets de danza clásica contemporánea cuya musa es el movimiento y su unión con el ritmo, algo que inició con la danza moderna y que ahora sigue siendo acentuado por este nuevo estilo coreográfico.

Con la interpretación de la CND de estos tres ballets en la Gala por su 50 Aniversario, el 24 de noviembre de 2013 en el Palacio de Bellas Artes, la danza clásica contemporánea se encuentra cada vez más asentada en México. Debido a que, si la agrupación de ballet representativa del país se preocupa por exponer obras de este estilo coreográfico, su trascendencia es evidente. Es un modo de bailar que aún está en movimiento, configurándose y, tal vez, perfeccionándose. A cada territorio que llega se le impregna una manera de bailar local, sobre todo cuando los coreógrafos de la región dan forma a una obra original que se apega a las características estéticas de este, pero, además, le agrega un estilo regional. La consolidación y aceptación a nivel nacional y mundial de la danza clásica contemporánea la ubican como una 
de las maneras de bailar que en este siglo XXI predomina en la danza teatral. No obstante, no es la única y la búsqueda de nuevos modos de expresarse mediante el movimiento es constante, lo que siempre dará lugar a nuevos estilos dancísticos y coreográficos que vayan de la mano de las necesidades estéticas de las sociedades.

\section{Referencias}

Abad, A. (2012). Historia del ballet y la danza moderna. Madrid: Alianza Editorial.

Alemany, M. (2012). Historia de la danza II. La danza moderna hasta la Segunda Guerra Mundial. Valencia: Piles.

Anderson, J. (2001). Los placeres de la historia de la danza. En Hilda Islas (comp.), De la danza al cuerpo y del cuerpo a la danza. pp. 161-170.

$\mathrm{Au}, \mathrm{S}$. (2012). Ballet and modern dance. Londres: Thames and Hudson.

Béjart, M. (1982). Un instante en la vida ajena. Buenos Aires: Gedisa / Emecé.

Béjart Ballet Lausanne. (s.f.). Pájaro de Fuego. Recuperado de https://www.bejart.ch/ballet/ loiseau-de-feu/

Bidault de la Calle, S. (2002). Danza, nación y revolución. En Maya Ramos Smith y Patricia Cardona Lang (dirs), La danza en México, visiones de cinco siglos (Volumen I, pp. 651-683). México: CEDINI-Danza / Escenología.

Dallal, A. (1996). La danza en México en el siglo XX. México: Consejo Nacional para la Cultura y las Artes.

Dallal, A. (2006). Estudios sobre el arte coreográfico. México: Universidad Nacional Autónoma de México.

Dallal, A. (2007). Los elementos de la danza. México: Universidad Nacional Autónoma de México.

Dance Consortium. International dance across the UK. (s.f.). Itzik Galili. Recuperado de http:// www.danceconsortium.com/features/choreographer/itzik-galili/

Fernández, J. (2013) Stravinsky al habla. Revista de Libros, Segunda Época. Recuperado de: http://www.revistadelibros.com/resenas/stravinsky-al-habla

Gombrich, E. \& Woodfield, R. (Eds.). (1997). Gombrich Esencial. (Trad. Fabián Chueca et al.). Nueva York: Phaidon.

Imbert, G. (2001). El cuerpo como producción social. En Hilda Islas (comp.), De la danza al cuerpo y del cuerpo a la danza (pp. 134-158). México: Instituto Nacional de Belllas Artes / Consejo Nacional para la Cultura y las Artes. 
Layson, J. (2001). Perspectivas históricas del estudio de la danza. En Hilda Islas (comp.). De la danza al cuerpo y del cuerpo a la danza (pp. 211-227). México: Instituto Nacional de Belllas Artes / Consejo Nacional para la Cultura y las Artes.

Ludden, K. (3 de diciembre de 2014). Re: Introducing: Joshua Beamish, Choreographer [blogspot]. Recuperado de http://www.huffingtonpost.com/ken-ludden/introducing-joshuabeamish_b_6256178.html

Moralejo, S. (2004). Formas elocuentes. Reflexiones sobre la teoría de la representación. Madrid: Akal.

MoveTheCompany. (2011). Allemande. Recuperado de http://joshuabeamish.com/repertoire/ allemande/

Palapa, F. (24 de noviembre de 2013). Tres estrenos engalanan el festejo por el 50 aniversario de la CND. La jornada. Recuperado de http://www.jornada.unam.mx/2013/11/24/cultura/ a02n1cul

Poveda, A. (2006). Entrevista a Itzik Galili “Poder de Seducción”. Por la danza. Recuperado de http://www.danza.es/multimedia/revista/entrevista-a-itzik-galili-poder-de-seduccion

Ramos Smith, M. (1979). La danza en México durante la época colonial. México: Editorial Patria / Secretaría de Educación Pública / Consejo Nacional para la Cultura y las Artes.

Tortajada, M. (2002). Transgresoras-constructoras del cuerpo y las imágenes. Las pioneras de la danza escénica mexicana del siglo XX-I: Nellie y Gloria Campobello. En Maya Ramos Smith y Patricia Cardona Lang (dirs), La danza en México, visiones de cinco siglos (Volumen I, pp. 685-715). México: Instituto Nacional de Belllas Artes / Consejo Nacional para la Cultura y las Artes.

Tortajada, M. (2002). Transgresoras-constructoras del cuerpo y las imágenes. Las pioneras de la danza escénica mexicana del siglo XX-II: Anna Sokolow y Waldeen. En Maya Ramos Smith y Patricia Cardona Lang (dirs), La danza en México, visiones de cinco siglos (Volumen I, pp. 717-739). México: Instituto Nacional de Belllas Artes / Consejo Nacional para la Cultura y las Artes.

Volli, H. (2001). Técnicas del cuerpo. En Hilda Islas (comp.), De la danza al cuerpo y del cuerpo a la danza (pp. 76-102). México: Instituto Nacional de Belllas Artes / Consejo Nacional para la Cultura y las Artes. 